\title{
$\alpha-S m o o t h$ muscle actin and proliferating cell nuclear antigen expression in focal segmental glomerulosclerosis: functional and structural parameters of renal disease progression
}

T.J.M. Geleilete ${ }^{1}$,

R.S. Costa ${ }^{2}$, M. Dantas 1 and T.M. Coimbra ${ }^{3}$

\author{
Departamentos de ${ }^{1}$ Clínica M édica, ${ }^{2}$ Patologia, and \\ ${ }^{3}$ Fisiologia, Faculdade de Medicina de Ribeirão Preto, \\ Universidade de São Paulo, Ribeirão Preto, SP, Brasil
}

\section{Correspondence \\ T.M. Coimbra \\ Departamento de Fisiologia \\ FMRP, USP \\ Av. Bandeirantes, 3900 \\ 14049-900 Ribeirão Preto, SP \\ Brasil \\ Fax: +55-16-633-0017 \\ E-mail: tmcoimbr@fmrp.usp.br \\ T.M. Coimbra and R.S. Costa were recipients of $\mathrm{CNPq}$ fellowships. Publication supported by FAPESP.}

Received August 11, 2000 Accepted May 17, 2001

\section{Abstract}

The aim of the present study was to investigate the expression of $\alpha$ smooth muscle actin ( $\alpha$-SM-actin) and proliferating cell nuclear antigen (PCNA) in renal cortex from patients with focal segmental glomerulosclerosis (FSGS) and their correlations with parameters of renal disease progression. We analyzed renal biopsies from 41 patients with idiopathic FSGS and from 14 control individuals. The $\alpha-S M-$ actin immunoreaction was evaluated using a score that reflected the changes in the extent and intensity of staining in the glomerular or cortical area. The PCNA reaction was quantified by counting the labeled cells of the glomeruli or renal cortex. The results, reported as median \pm percentile $(25$ th; 75 th $)$, showed that the $\alpha$-SM-actin scores in the glomeruli and tubulointerstitium from the renal cortex were 2.0 $(2.0 ; 4.0)$ and $3.0(3.0 ; 4.0)$, respectively, in patients with FSGS, and $0.5(0.0 ; 1.0)$ and $0.0(0.0 ; 0.5)$ in the controls. The number of PCNApositive cells per glomerulus and graded field of tubulointerstitium from the renal cortex was $0.2(0.0 ; 0.4)$ and $1.1(0.3 ; 2.2)$, respectively, for patients with FSGS, and $0.0(0.0 ; 0.5)$ and $0.0(0.0 ; 0.0)$ for controls. The present data showed an increase of $\alpha$-SM-actin and PCNA expression in glomeruli and renal cortex from FSGS patients. The extent of immunoreaction for $\alpha$-SM-actin in the tubulointerstitial area was correlated with the intensity of proteinuria. However, there was no correlation between the kidney expression of these proteins and the reciprocal of plasma creatinine level or renal fibrosis. These findings suggest that the immunohistochemical alterations may be reversible.

\section{Introduction}

The progression of renal disease depends, among other factors, on the interaction between kidney cells and cytokines (1). Cytokines act on renal cells (tubular cells, mesan-
Key words

- $\alpha$-Smooth muscle actin

- Proliferating cell nuclear antigen

- PCNA

- Focal segmental glomerulosclerosis

- Proteinuria

- Renal failure

- Renal disease progression

- Renal fibrosis 
of proliferating cell nuclear antigen (PCNA) and $\alpha$-SM-actin expression by renal cells may be related to renal disease progression. However, although some studies have suggested that markers of renal cell activation and proliferation such as immunostaining of renal biopsies for $\alpha$-SM-actin and PCNA might be useful diagnostic and/or prognostic indicators in glomerular diseases (3-5), other studies have shown that these immunohistochemical changes observed during renal disease may be reversible (6-8).

The $\alpha$-SM-actin isoform is normally expressed by vascular smooth muscle cells but interstitial fibroblasts and mesangial and tubular cells can also express this protein in a variety of glomerular diseases. There is some experimental evidence suggesting that transforming growth factor- $\beta$ (TGF- $\beta$ ) and platelet-derived growth factor (PDGF) can induce phenotypic modifications of these cells $(9,10)$. The $\alpha$-SM-actin synthesis upregulated by these cells is frequently associated with increased cell proliferation and increased extracellular matrix production $(1,5$, $8,11)$. PCNA is an acidic nuclear protein whose levels are increased from the late G1 to the $\mathrm{S}$ phase of the cell cycle and whose detection parallels other standard methods of assessing cell proliferation such as BrdU labeling and Ki-67 staining $(12,13)$. The aim of the present study was to investigate the expression of $\alpha$-SM-actin and PCNA in renal cortex from patients with focal segmental glomerulosclerosis (FSGS) and from control individuals and their correlations with parameters of renal disease progression.

\section{Subjects and Methods}

\section{Subjects}

We analyzed renal biopsies from patients with idiopathic FSGS $(\mathrm{N}=41,19$ males and 22 females) and from 14 control individuals obtained between 1987 and 1998 at the University Hospital of Ribeirão Preto. The study was started in February 1998 and patient follow-up ranged from 2 to 120 months (mean \pm SEM, $43.6 \pm 6$ months). Each patient was submitted to only one biopsy. The diagnosis of idiopathic FSGS was based on the exclusion by clinical and laboratory evaluation of possible causes of secondary FSGS such as syphilis, hepatitis $\mathrm{B}$ and $\mathrm{C}$ virus infection, HIV, neoplastic diseases, systemic lupus erythematosus, and other collagen diseases. The preserved renal areas of patients submitted to nephrectomy were used as control. The age range of the patients was 3-74 years and the age range of the controls was 2-79 years. Patient plasma creatinine levels ranged from 0.4 to $3.4 \mathrm{mg} / \mathrm{dl}$ and proteinuria from 1.0 to $20.8 \mathrm{~g} / 24 \mathrm{~h}$. Plasma creatinine and proteinuria were determined at least every three months during the evolution of the disease. Twenty-two patients presented high arterial pressure (systolic pressure $>140$ $\mathrm{mmHg}$ and diastolic pressure $>90 \mathrm{mmHg}$ ). After the biopsy, 27 patients were treated with a daily high dose of prednisone $(1 \mathrm{mg}$ $\mathrm{kg}^{-1}$ day $\left.^{-1}\right)$ for 8 weeks. Seven of them presented partial remission (proteinuria $<3 \mathrm{~g} / 24$ h) and three complete remission (proteinuria $<0.3 \mathrm{~g} / 24 \mathrm{~h}$ ). Cyclophosphamide therapy was introduced for patients with steroid-unresponsive FSGS (proteinuria $>3.5 \mathrm{~g} / 24 \mathrm{~h}$ ) or with relapse (proteinuria $>3 \mathrm{~g} / 24 \mathrm{~h}$ ). However, 17 of these patients failed to respond to treatment. All control subjects had normal plasma creatinine levels (mean $\pm \mathrm{SEM}, 0.80$ $\pm 0.17 \mathrm{mg} / \mathrm{dl}$ ) and normal arterial pressure and none had urinary abnormalities (proteinuria was not detected by routine methods). The research was approved by the Ethics Committee of the University Hospital of Ribeirão Preto and written informed consent was obtained from all the participants in the study.

\section{Morphological and immunofluorescence evaluation}

The tissue obtained by renal biopsy from 
41 patients with idiopathic FSGS was fixed in Bouin's solution, embedded in paraffin, cut into $4-\mu \mathrm{m}$ sections and stained with hematoxylin and eosin, Masson trichrome and methenamine silver. Immunofluorescence analysis of all biopsies was also performed using anti-IgG, anti-IgA, anti-IgM, anti-C3, anti-C1q, anti-kappa, anti-lambda and antifibrinogen antibodies in order to confirm the diagnosis. The percentage of glomeruli exhibiting focal or global glomerular sclerosis was determined for each biopsy. The number of glomeruli per biopsy ranged from 5 to 30 (12 \pm 7 glomeruli/biopsy). Tubulointerstitial fibrosis was scored as $1=$ absent, $2=$ mild and focal, $3=$ moderate and focal, $4=$ severe and focal or mild and diffuse, and $5=$ severe and diffuse.

\section{Immunohistochemical studies}

The immunohistochemical studies were performed using a murine monoclonal antibody to an $\mathrm{NH}_{2}$-terminal synthetic form of $\alpha$-SM-actin (Dako, Glostrup, Denmark) or a monoclonal anti-PCNA antibody (Sigma Chemical Co., St. Louis, MO, USA). Fourmicrometer sections of biopsy tissue fixed in Bouin's solution were processed by an indirect immunoperoxidase technique as described (14).

Sections were incubated overnight at $4{ }^{\circ} \mathrm{C}$ with 1:1000 $\alpha$-SM-actin antibody or for 30 $\mathrm{min}$ at room temperature with anti-PCNA antibody. The reaction product was detected with an avidin-biotin-peroxidase complex (Vector Labs., Burlingame, CA, USA). The color reaction was developed with 3,3-diaminobenzidine (Sigma), and the material was counterstained with methyl green (Sigma), dehydrated and mounted. Negative controls consisted of the omission of the primary antibody in the reaction and of substitution of primary antibody with equivalent concentrations of normal murine IgG. Glomerular expression of $\alpha$-SM-actin was graded semi-quantitatively according to the following scale (15): $0=$ none, $1=$ trace mesangial staining, 2 = weak, segmental mesangial staining, usually involving a small minority of glomeruli present, $3=$ strong, segmental mesangial staining, usually involving a majority of glomeruli present, and $4=$ strong, diffuse mesangial staining, usually involving all glomeruli present. The $\alpha$ SM-actin immunoreaction in the tubulointerstitium of the renal cortex was scored as follows: 0 = absent staining, $1=$ weak staining with focal distribution, $2=$ moderate with focal distribution, 3 = strong with focal distribution or weak and diffuse, and $4=$ strong and diffuse. A score was assigned to each biopsy, mainly reflecting the changes in the extent rather than intensity of staining. The PCNA reaction was quantified by counting the labeled cells of the glomerular tufts or grid field from the renal cortex, measuring $0.1885 \mathrm{~mm}^{2}$ each, and the mean score per biopsy was calculated by dividing the number of PCNA-positive cells of glomeruli or cortex, respectively, by the number of glomeruli or fields present in each biopsy. The number of fields analyzed per biopsy ranged from 6 to 62 (mean, 18.3).

\section{Determination of plasma creatinine}

Plasma creatinine was measured by the Jaffé method (16) and the plasma creatinine level at the time of biopsy was used to determine any correlation between staining for $\alpha$ SM-actin or PCNA in renal cortex and $1 /$ plasma creatinine $\left(1 / \mathrm{P}_{\text {creat }}\right)$.

\section{Statistical analysis}

The Spearman correlation coefficient for nonparametric data was used to determine any significant correlation between staining for $\alpha$-SM-actin or PCNA in the renal cortex and glomeruli and some parameters of renal function and structure of patients with FSGS. The data concerning $\alpha$-SM-actin score and PCNA obtained from control individuals and 
from patients with FSGS were submitted to the Mann-Whitney test. The level of significance considered was $\mathrm{P}<0.050$. Plasma creatinine and albumin data are expressed as mean \pm SEM and the data concerning scores for tubulointerstitial fibrosis, percentage of

Table 1. Expression of $\alpha$-smooth muscle actin ( $\alpha$-SM-actin)and proliferating cell nuclear antigen (PCNA) (positive cells/glomerulus or per graded field) in glomeruli or in the tubulointerstitial area (TI) from the renal cortex of patients with focal segmental glomerulosclerosis (FSGS) and of control individuals.

\begin{tabular}{llllll}
\hline & \multicolumn{2}{c}{$\alpha$-SM-actin (score) } & & \multicolumn{2}{c}{ PCNA (positive cells) } \\
\cline { 2 - 3 } \cline { 6 - 7 } & Glomeruli & TI & & Glomeruli & TI \\
\hline FSGS & $2.0(2.0 ; 4.0)^{*}$ & $3.0(3.0 ; 4.0)^{*}$ & & $0.2(0.0 ; 0.4)$ & $1.1(0.3 ; 2.2)^{*}$ \\
Control & $0.5(0.0 ; 1.0)$ & $0.0(0.0 ; 0.5)$ & & $0.0(0.0 ; 0.5)$ & $0.0(0.0 ; 0.0)$
\end{tabular}

Data are reported as median and percentile (25th; 75th).

$* \mathrm{P}<0.001$ compared to control (Mann-Whitney test).

Figure 1. Expression of $\alpha-$ smooth muscle actin ( $\alpha$-SM-actin) in glomeruli $(G)$ or in the tubulointerstitial area (TI) from the renal cortex of patients with focal segmental glomerulosclerosis (FSGS, $N=41$ ) and of control individuals $(C, N=14)$. The median is shown as a horizontal line.

Figure 2. Expression of proliferating cell nuclear antigen (PCNA) (positive cells/glomerulus or per graded field) in glomeruli (G) or in the tubulointerstitial area (TI) from the renal cortex of patients with focal segmental glomerulosclerosis (FSGS, $N=41$ ) and of control individuals $(\mathrm{C}, \mathrm{N}=8)$. The median is shown as a horizontal line.
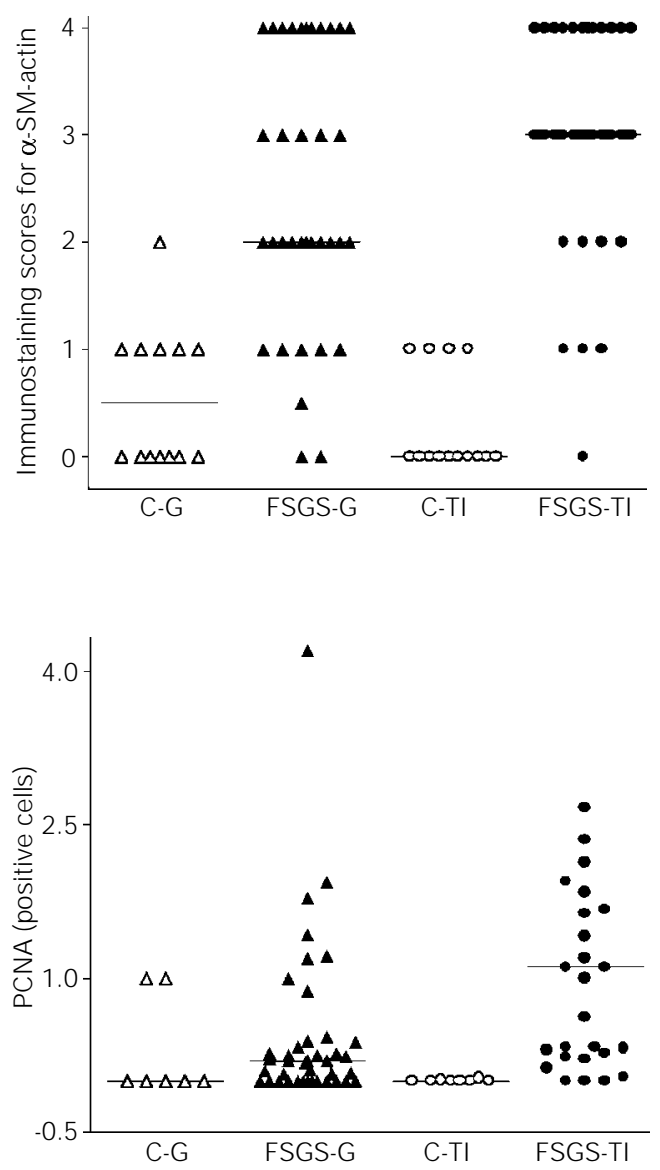

glomeruli with sclerosis, $\alpha$-SM-actin scores, and PCNA in the renal cortex and glomeruli are expressed as median and percentile (25th; 75th).

\section{Results}

We observed that the percentage of glomeruli with sclerosis was $44.5(25.0 ; 68.3)$ and the score for tubulointerstitial fibrosis was $2.0(1.0 ; 3.0)$. The plasma creatinine of these patients was $1.62 \pm 0.18 \mathrm{mg} / \mathrm{dl}$ (mean \pm SEM) at the time of biopsy and $3.26 \pm 0.61$ $\mathrm{mg} / \mathrm{dl}$ at the last determination. We found a negative correlation between $1 / \mathrm{P}_{\text {creat }}$ at the time of biopsy and the score for tubulointerstitial fibrosis $(r=-0.463, P=0.002)$. Eighteen of the patients presented a decline of renal function within $43.6 \pm 6.00$ months, with a plasma creatinine level $>2.00 \mathrm{mg} / \mathrm{dl}$ at the last evaluation. Proteinuria was $7.36 \pm$ $0.65 \mathrm{~g} / 24 \mathrm{~h}$ (mean $\pm \mathrm{SEM}$ ) at the time of biopsy and $4.72 \pm 1.42 \mathrm{mg} / 24 \mathrm{~h}$ at the last determination, and we did not observe any correlation between proteinuria and $1 / \mathrm{P}_{\text {creat }}$ at the time of biopsy or the score for tubulointerstitial fibrosis.

Our data also showed an increase of $\alpha$ SM-actin expression in glomeruli and in the tubulointerstitial area from the renal cortex and of PCNA expression in the tubulointerstitial area from the renal cortex of FSGS patients (Table 1, Figures 1, 2, 3 and 4) $(\mathrm{P}<0.001) . \alpha$ $\mathrm{SM}$-actin expression in the glomeruli from these patients was correlated with PCNA expression $(r=0.47, P=0.003)$. We also observed that the immunoreaction for $\alpha$-SMactin in the tubulointerstitial area was correlated with the intensity of proteinuria at the time of biopsy in FSGS patients $(\mathrm{r}=0.363, \mathrm{P}=$ 0.021) (Figure 5). However, we did not find any correlation between the kidney expression of these proteins and $1 / \mathrm{P}_{\text {creat }}$ at the time of biopsy or between the expression of $\alpha$-SMactin or PCNA in the glomeruli and tubulointerstitial area and the percentage of glomerulosclerosis or the score for tubulointerstitial fi- 
brosis in the kidneys of these patients. We also did not observe any correlation between the kidney expression of $\alpha$-SM-actin or PCNA in the glomeruli and tubulointerstitial area and blood pressure at the time of biopsy or the response to treatment.

\section{Discussion}

Our data showed an increase of $\alpha$-SMactin expression in glomeruli and tubulointerstitial area from the renal cortex and of PCNA in the tubulointerstitial area from the renal cortex of idiopathic FSGS patients. Increased expression of these proteins during the evolution of glomerular disease was observed by several investigators (2-8). These alterations were probably induced by some cytokines like TGF- $\beta$ and PDGF and by endothelin and angiotensin II and were related to renal injury $(1,9,10)$. Increased renal content and production of these polypeptides have been observed in several glomerular diseases $(1,14,17-22)$, probably induced by glomerular hypertension or hypertrophy, macrophage infiltration, high renal levels of angiotensin and proteinuria observed in these patients $(1,14,23-26)$.

We also observed that the immunoreaction for $\alpha$-SM-actin in the tubulointerstitial area was correlated with the intensity of proteinuria at the time of biopsy in idiopathic FSGS patients. This fact suggests that the renal handling of protein induced activation of the interstitial cells. It has been suggested that proteins filtered by the glomeruli could be toxic for tubule cells (27-29). Studies with tubule cell cultures have shown that some proteins such as IgG and albumin induce an increase in the production of inflammatory and vasoactive factors $(27,28)$. This observation can explain why greater proteinuria is frequently associated with more severe tubulointerstitial damage.

We did not find any correlation between the kidney expression of $\alpha$-SM-actin or PCNA and $1 / \mathrm{P}_{\text {creat }}$ at the time of biopsy. This finding might be explained, in part, by the possibility that these alterations detected by immunohistochemical techniques are reversible. Although some studies have suggested that markers of renal cell activation and pro-
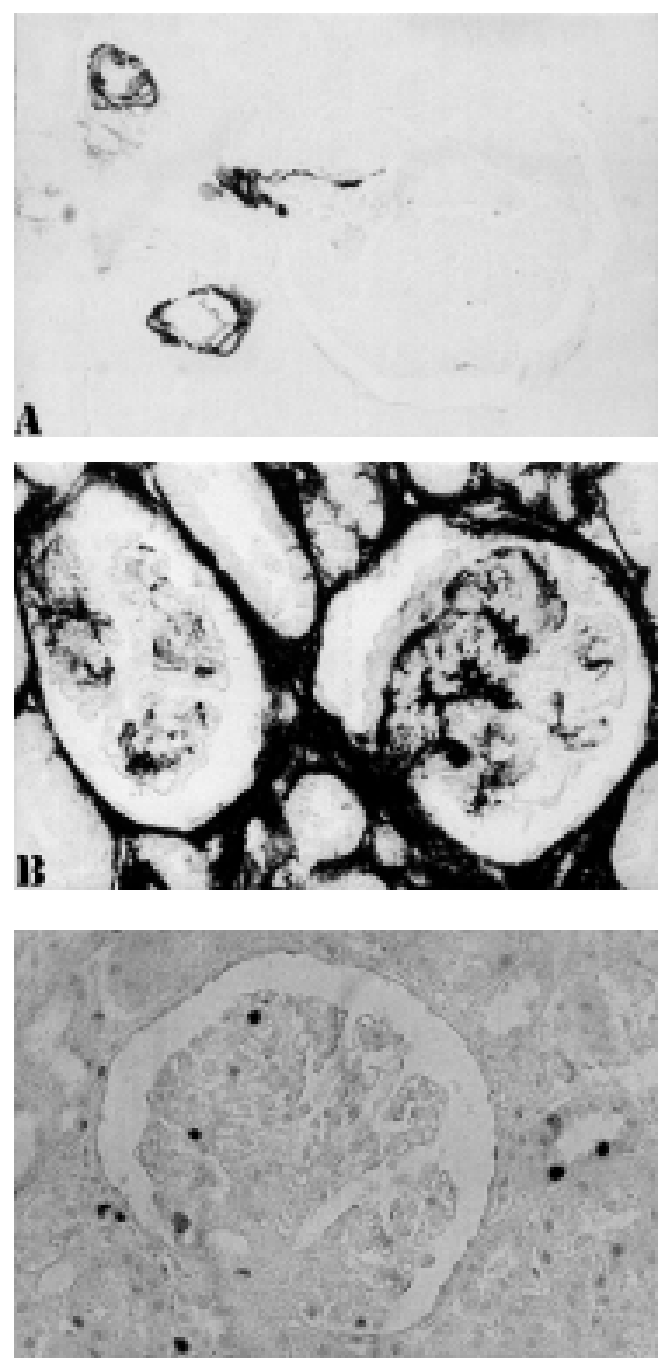

Figure 4. Immunolocalization of proliferating cell nuclear antigen (PCNA) in the renal cortex from a patient with focal segmental glomerulosclerosis using an antiPCNA antibody. Note the presence of more than 2 PCNA-positive cells per glomerulus and tubulointerstitial area, while the control shows less than 1 PCNApositive cell per glomerulus or tubulointerstitial area (original magnification: 250X).

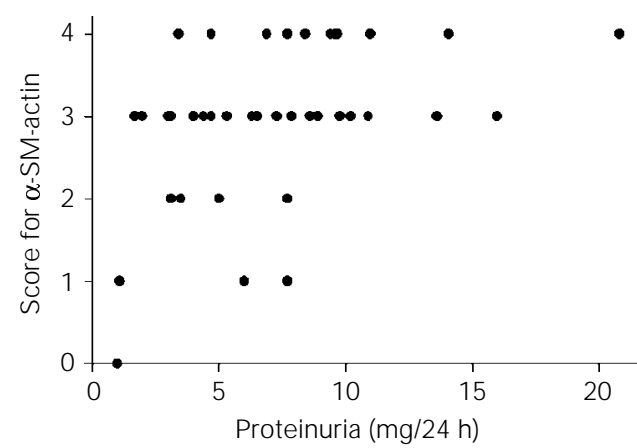

Figure 5. Correlation between $\alpha$-smooth muscle actin ( $\alpha$-SMactin) score in the tubulointerstitial area from the renal cortex and proteinuria at the time of biopsy $(r=0.363, P=0.021)$. 
liferation such as $\alpha$-SM-actin and PCNA might be useful diagnostic and prognostic indicators in glomerular diseases, there are some studies showing that these alterations detected by immunochemical techniques in renal diseases can be reduced during the evolution to fibrosis or to recovery (6-8). Hattori et al. (8) performed repeat renal biopsies in patients with FSGS with cellular lesions and observed reduced glomerular $\alpha-$ SM-actin expression associated with progression to glomerular scar formation. Groma et al. (7) demonstrated increased $\alpha$-SM-actin expression in types of glomerulonephritis with different prognosis. Boukhalfa et al. (6), after studying several glomerulopathies, concluded that $\alpha$-SM-actin expression in the interstitial area was correlated with interstitial fibrosis but $\alpha$-SM-actin expression in the glomeruli was reduced with the progression of glomerulosclerosis. We also did not observe any correlation between the kidney expression of $\alpha$-SM-actin or PCNA in the glomeruli and tubulointerstitial area and the percentage of glomerulosclerosis or the score for tubulointerstitial fibrosis in the kidneys of these patients. Taken together, these findings suggest that the cellular activation verified during the course of renal disease, although important for renal damage, can be reduced during the evolution of renal disease to fibrosis or to recovery. On the other hand, we also have to consider that 18 of these patients presented loss of renal function within a relatively short time $(43.60 \pm$ 6.00 months).

$\alpha$-SM-actin expression in the glomeruli was correlated with PCNA expression, as also reported by Johnson et al. (11). These investigators found that $\alpha$-SM-actin expression by mesangial cells was associated with active proliferation of these cells.

The present data show an increase of $\alpha$ SM-actin expression in glomeruli and tubulointerstitial area from the renal cortex and of PCNA in the tubulointerstitial area from the renal cortex of idiopathic FSGS patients. We also observed that the immunoreaction for $\alpha$-SM-actin in the tubulointerstitial area was correlated with the intensity of proteinuria in FSGS patients. However, we did not find any correlation between the kidney expression of these proteins and $1 / \mathrm{P}_{\text {creat }}$ level at the time of biopsy or renal fibrosis.

\section{Acknowledgments}

We wish to express our appreciation to Cleonice G.A. da Silva and Erika Delloiagno for expert technical assistance.

\section{References}

1. Eddy AA (1996). Molecular insights into renal interstitial fibrosis. J ournal of the American Society of Nephrology, 7: 24952508.

2. Howie AJ , Rowlands DC, Reynolds GM \& Barnes AD (1995). Measurement of proliferation in renal biopsy specimens: Evidence of subclinical tubular damage in the nephrotic syndrome. Nephrology, Dialysis, Transplantation, 10: 2212-2218.

3. Zhang G, Moorhead PJ \& El Nahas AM (1995). Myofibroblasts and progression of experimental glomerulonephritis. Experimental Nephrology, 3: 308-318.

4. Hewitson TD \& Becker GJ (1995). Interstitial myofibroblasts in IgA glomerulone- phritis. American J ournal of Nephrology, 15: 111-117.

5. Muchaneta-Kubara EC \& El Nahas AM (1997). Myofibroblast phenotypes expression in experimental renal scarring. Nephrology, Dialysis, Transplantation, 12: 904-915.

6. Boukhalfa G, Desmouliere A, Rondeau E, Gabbiani G \& Sraer JD (1996). Relationship between alpha-smooth muscle actin expression and fibrotic changes in human kidney. Experimental Nephrology, 4: 241247.

7. Groma V, Marcussen N \& Olsen S (1997). A quantitative immunohistochemical study of the expression of mesangial al- pha-smooth muscle actin and proliferation marker Ki-67 in glomerulonephritis in man. Virchows Archives, 431: 345-350.

8. Hattori M, Horita S, Yoshioka T, Yamaguchi Y, Kawaguchi H \& Ito K (1997). Mesangial phenotypic changes associated with cellular lesions in primary focal segmental glomerulosclerosis. American J ournal of Kidney Diseases, 30: 632-638.

9. Desmouliere A, Geinoz A, Gabbiani F \& Gabbiani G (1993). Transforming growth factor-beta-1 induces alpha-smooth muscle actin expression in granulationtissue myofibroblasts and in quiescent and growing cultured fibroblasts. J ournal of Cell Biology, 122: 103-111. 
10. Tang WW, Ulich TR, Lacey DL, Hill DC, Qi MY, Kaufman SA, Van GY, Tarpley JE \& Yee JS (1996). Platelet-derived growth factor-BB induces renal tubulointerstitial myofibroblast formation and tubulointerstitial fibrosis. American J ournal of $\mathrm{Pa}-$ thology, 148: 1169-1180.

11. J ohnson RJ, lida H, Alpers CE, Majesky MW, Schwartz SM, Pritzl P, Gordon K \& Gown AM (1991). Expression of smooth muscle cell phenotype by rat mesangial cells in immune complex nephritis. Alphasmooth muscle actin is a marker of mesangial cell proliferation. J ournal of Clinical Investigation, 87: 847-858.

12. Kubben FJ GM, Peeters-Haesevoets $A$, Engels LGJ B, Baeten CGMI, Schutte B, Arends J W, Stockbrugger RW \& Blijham GH (1994). Proliferating cell nuclear antigen (PCNA): a new marker to study coIonic cell proliferation. Gut, 35: 530-535.

13. Weisgerber UM, Boeing $H$, Nemitz $R$, Raedsch R \& Waldherr R (1993). Proliferation cell nuclear antigen (clone 19A2) correlates with 5-bromo-2-deoxyuridine labeling in human colonic epithelium. Gut, 34: 1587-1592.

14. Kliem V, J ohnson RJ, Alpers CE, Yoshimura A, Couser WG, Koch KM \& Floege J (1996). Mechanism involved in the pathogenesis of tubulointerstitial fibrosis in 5/6 nephrectomized rats. Kidney International, 49: 666-678.

15. Alpers CE, Hudkins KL, Gown AM \& J ohnson RJ (1992). Enhanced expression of "muscle-specific" actin in glomerulonephritis. Kidney International, 41: 11341142.

16. Haygen HN (1953). The determination of endogenous creatinine in plasma and urine. J ournal of Clinical and Laboratory Investigation, 17: 381-387.

17. Border WA, Okuda S, Languino LR, Sporm MB \& Ruoslahti E (1990). Suppression of experimental glomerulonephritis by antiserum against transforming growth factor-ß. Nature, 346: 371-374.

18. Dominguez GCS, Costa RS, Dantas $M$, Kimachi T, Piuci CR \& Coimbra TM (1998). Transforming growth factor- $ß$ activity in urine of patients with glomerulonephritis is related to their renal functional and structural changes. Nephrology, 4: 31-36.

19. de Freitas ASM, Coimbra TM, Costa RS \& Baroni EA (1998). Urinary transforming growth factor- $\beta$ excretion and renal production of TGF- $\beta$ in rats with subtotal renal ablation: Effect of enalapril and nifedipine. Nephron, 78: 302-309.

20. Coimbra T, Wiggins RC, J ung WN, Merritt S \& Phan SH (1991). Transforming growth factor-ß production in anti-glomerular basement membrane disease in the rabbit. American J ournal of Pathology, 138: 223-234.

21. Yamamoto $T$, Noble NA, Cohen $A H$, Nast CC, Hishida A, Gold LI \& Border WA (1996). Expression of transforming growth factor-ß isoforms in human glomerular diseases. Kidney International, 49: 461-469.

22. Niemir Zl, Stein $\mathrm{H}$, Noronha IL, Kruger $\mathrm{C}$, Andrassy K, Ritz E \& Waldherr R (1995). PDGF and TGF- $\beta$ contribute to the natural course of human-IgA glomerulonephritis. Kidney International, 48: 1530-1541.

23. Cortes $P$, Riser BL, Zhao $X Y \& \&$ Narins RG (1994). Glomerular volume expansion and mesangial cell mechanical strain: Mediators of glomerular pressure injury. Kidney
International, 45 (Suppl): S11-S16.

24. Johnson RJ, Alpers CE, Yoshimura A, Lombardi D, Pritzl P, Floege J \& Schwartz SM (1992). Renal injury from angiotensin II-mediated hypertension. Hypertension, 19: 464-474.

25. Kagami S, Border WA, Miller DE \& Noble NA (1994). Angiotensin II stimulates extracellular matrix protein synthesis through induction of transforming growth factor-ß expression in rat glomerular mesangial cells. J ournal of Clinical Investigation, 93: 2431-2437.

26. Eddy AA, McCulloch L, Adams J \& Liu E (1989). Interstitial nephritis induced by protein-overload proteinuria. American J ournal of Pathology, 135: 719-733.

27. Zoja C, Donadelli R, Colleoni S, Figliuzzi $M$, Bonazzola S, Morigi $M \&$ Remuzzi $G$ (1998). Protein overload stimulates RANTES production by proximal tubular cells depending on NF-kB activation. Kidney International, 53: 1608-1615.

28. Zoja C, Morigi M, Figliuzzi M, Bruzzi I, Oldroyd S, Benigni A, Ronco PM \& Remuzzi G (1995). Proximal tubular cell synthesis and secretion of endothelin-1 on challenge with albumin and other proteins. American J ournal of Kidney Diseases, 26: 934-941.

29. Baroni EA, Costa RS, Volpini RA \& Coimbra TM (1999). Sodium bicarbonate treatment reduces renal injury, renal production of TGF- $\beta$, and urinary transforming growth factor- $ß$ excretion in rats with doxorubicin-induced nephropathy. American J ournal of Kidney Diseases, 34: 328337. 